\title{
Proposal of Methodology for Evaluation of Ergonomics of Teaching Materials Using Eye Tracking
}

\author{
https://doi.org/10.3991/ijet.v15i24.19319 \\ Pavel Smolka $\left({ }^{\bowtie}\right)$, Martin Žáček, Petra Konečná \\ University of Ostrava, Ostrava, Czechia \\ pavel.smolka@osu.cz
}

\begin{abstract}
Educational materials are a key component of the educational process. In this respect, it is an instrument that is essential throughout the education process and where quality plays a key role. The quality of educational materials must be assessed in terms of expertise and timeliness, and in terms of observance and application of didactic and pedagogical principles. Only highquality educational materials bring greater efficiency to the entire education process. An essential aspect of assessing the quality of educational materials is also their ergonomics. That is, assessing whether the educational material works in accordance with the author's ideas. The principle of ergonomics, which includes comprehensibility and user-friendliness, is already commonly used in the design of web pages or advertising flyers. Their aim is also to communicate information and lead the attention of the reader. This article is devoted to the definition of the methodology by which we evaluate this ergonomics for educational materials and based on research we are able to formulate recommendations in this area.
\end{abstract}

Keywords—Eye tracking, ergonomics, quality, educational material

\section{Introduction}

The current primary and secondary education in the Czech Republic is characterized by considerable diversity in the area of the creation of educational materials. This diversity has been largely supported by operational programs implemented in the field of education, which allowed the creation of educational materials. This trend was relatively massive in the 2007-2013 programming period, and partially it is supported in the 2014-2020 programming period too. In the 2007-2013 programming period, the scope and form of the educational materials were defined by the beneficiary. His primary duty was to publish these materials on a publicly accessible portal. The educational materials produced in this way, were referred to as DUMs (Digital Learning Materials). According to the SAO's finding, several hundred thousand materials were produced in this programming period [10]. The basic assessment that these materials underwent was economic adequacy. The created and published materials did not undergo the classical review procedure, their validity was determined by the popularity 
on the portal www.dumy.cz rated by stars by the professional public and the user public. However, the evaluation criteria are not known.

In the 2014-2020 programming period, much less support was defined for the creation of new or innovated materials. One of these calls defines a new standard DVZ (Digital Educational Resource). In this case, the criteria for assessing the quality of DVZ were defined by the National Institute for Education of the Czech Republic [6]. Even in this case, it is rather a technological evaluation of emerging educational materials that do not reflect their true quality.

From the above conclusions, it is possible to define a clear need for assessing the quality and ergonomics of emerging learning materials in order to increase the efficiency of their deployment. The current definition of the quality of educational materials is based on the general definition of the quality of the teaching process. In general, it is possible to draw inspiration from the book Quality Education [9], which addresses the general structure of the educational unit and hence the general structure of educational material in terms of pedagogy and didactics.

The open question is the situation in the construction of teaching material, where the structure is respected in terms of didactics and pedagogy, but the material is not appropriately arranged in terms of ergonomics. In this case, the best structure is degraded by improper arrangement and the learning material may not be effective. The design requirements are largely influenced by the technologies used by the target group in their daily lives. Development in this area is relatively rapid and defines the need for constant updating of the arrangement of suitably structured materials. In terms of data needed for the update, we can start with questionnaire surveys, which are burdened with considerable subjectivity and idealization, or with technologies that allow us to capture both the conscious and subconscious behaviour of the respondent.

\section{Visual Memory}

With the advancement of modern technology of today's students mainly use visual memory. The visualization acquaints students with figures that the teacher cannot provide - mainly used in natural sciences. However, we need to adapt our interpretation of the curriculum through visualization - have an effect on the eyesight of student. It is generally known [11] that eyesight is about 10 times faster than the hearing channel, i.e. the amount of information that we get insight at the same time is 10 times that of hearing [2].

\subsection{Benefits}

- Visual aids (such as figures, graphs, animation animations in electronic form) attract the attention of students and thus increases motivation;

- Stimulate students' visual memory;

- Increasing the amount of stored knowledge $-87 \%$ of all information we perceive sight, while by hearing we perceive only $9 \%$. 
Visual memory is intended for seen information: it is important in terms of object perception, keeping it in memory and subsequent equipment. It is a kind of short-term memory, which processes the information that we receive for the use of the eyesight.

Our goal in this respect is to study and experiment with visual perception because our visual experience changes frequently stage processing of visual information and affect our ability to see.

It is therefore desirable to use visual memory at work as we need to remember (not only hear but also see) any data represented in some form (be it figures, continuous text, graphs, tables, drawings, symbols or anything else), and the student can help with that to himself.

We can encounter the visual distinction at visual memories. The visual distinction of detail helps students to see differences in visual aids (e.g. figures or graphs) [5].

Further uses visual analysis and synthesis. The visual analysis helps students to find only a part of them, which is important for them. The Visual synthesis helps students to integrate the individual parts together (for example, graph and information - see our experiment). The visual memory helps students to see pictures and later to remember words. The visual memory is essential for the successful perception of the teaching substance at school.

\section{Description of Eye Tracking Technology}

The principle of Eye Tracking is based on sensing eye movement using a device that monitors eye movements. This principle has been used in the fields of psychology, medicine, engineering, marketing and education. In particular, the field of marketing studies of respondents' behaviour is very interesting from the point of view of this article because it addresses the quality and ergonomics of the input. The principle of Eye Tracking is based on sensing eye movement using a device that monitors eye movements. This principle has been used in the fields of psychology, medicine, engineering, marketing and education [1]. In particular, the field of marketing studies of respondents' behaviour is very interesting from the point of view of this article because it addresses the quality and ergonomics of the input. By tracking eye movement while viewing a catalogue, e-shop, or advertising flyer, it is possible to measure the attention that a potential customer pays to individual products. Another result that this investigation brings us is the trajectory of eye movement across the area of interest. The measurement process is defined by a clearly defined time and so it is possible to determine the sequence of the respondent's concentration on individual parts of the examined area.

Eye movement sensing can be divided into three basic groups according to the method used, which focus on measuring eye movement in the head or measure the point of view. For this measurement, we use devices that are commonly referred to as eye trackers. ETs most often use video to determine eye movement or measure electrical potential. 


\subsection{Mechanical methods of eye movement sensing}

The method of mechanical sensing eye movement is characterized by high precision, but relatively high discomfort. In this case, it is the application of an optical reference object to a contact lens that is applied directly to the eye. The basic method uses a wire coil that is measured by moving through an electromagnetic field. This is a relatively invasive method. This method measures the position of the eye relative to the head and is generally not suitable for measuring viewing points.

\subsection{Videoclography}

These are techniques that record the distinctive features of the eyes during rotation I translation, such as the apparent pupil shape, the position of the limbus (iris and whites) and the corneal reflection close to the light source (often infrared). Automatic limbus tracking often involves the use of photodiodes mounted on the frame of the spectacles, and almost always involves the use of invisible, usually infrared, lighting. Some of these methods require the head to be fixed. The results obtained with this measurement are not suitable for the calculation of attention rate.

\subsection{Electrooculography}

Electrooculography is the most used method of monitoring eye movements. The essence of this method is to measure the differences in the electrical potential of the skin by using electrodes placed around the eye that generate changes in the movement of the eyeball. This technique measures eye movements relative to the head position and is therefore generally not suitable for measuring viewing points unless the head position is measured. Electrooculography has two great advantages:

- Wearing contact lenses or glasses does not affect measurement

- Not too expensive.

\subsection{Recording of eye movements}

Eye trackers record large amounts of data in one second, which corresponds to the oscillations of the human eye. Most of these devices are able to track the right and left eyes separately. This raw data is filtered and aggregated into a form that allows us to capture the fixation of the eye and the oscillation rate of the eye. The key record is the fixation of the eye, which is the state when the eye is at rest and in the range of a few ms to $s$. However, even the fixed eye performs micro-movements. These are tremor, drift or oscillation (saccades). For data processing and recognition of the abovementioned phenomena, the algorithms that enable us to determine fixation are key. These include the "dispersion-based" algorithm, the velocity-based algorithm, or the "Bidden Markov" algorithm [3] [4]. 


\section{Proposal of Methodology of Measurement of Ergonomics of Educational Material}

The aim of the proposed methodology is primarily to assess the ergonomics of the teaching material and thus its effectiveness with the use of eye tracking. In terms of results, we focus on two basic measured quantities. This is primarily the trajectory of the eye in the context of teaching material over time. From this trajectory, we infer the student's passage through the learning material in the order it was intended.

Additional criterion is then measured map attention to ergonomics in the context of the resource is able to indicate problematic areas in terms of understanding. The expected use of this methodology is applicable to both digital teaching materials and classical printed materials. There is a certain need to devote to teaching materials designed for frontal exposure of students, typically presentations and similar materials, and a slightly different approach to assessing the ergonomics of teaching materials designed for individual work.

\subsection{PART A calibration}

The first part consists of individual calibration of the device before each individual measurement and for each individual workplace. This step respects the individuality of each respondent and increases the relevance of the measured values. Individual calibration not only respects individual differences, but is able to cope with distortion in respondents who wear glasses or wear lenses.

\subsection{PART B self-measurement}

The methodology used for educational materials used in frontal exposure. In view of the nature of this type of material, it is necessary to perform two measurements. The first measurement is carried out individually and separately, the second group. In the case of group metering, the result of the learning group is captured as a result.

1. Individual measurement and determination of attention map in laboratory conditions

a) Convert material to form usable in OGAMA (Open Gaze and Mouse Analyzer) [7].

b) Recording of an audio record of the clock and its integration into the researched material in the OGAMA environment.

c) Exposure of selected samples of pupils.

2. Evaluate metrics

a) Group measurement

b) Connection of real-time camera recordings within the teaching unit to the OGAMA environment.

c) Exposure of selected sample of students. 
d) Evaluate metrics.

3. The methodology is designed for teaching materials that the student works independently with

a) Digitization of worksheets to allow interactive completion.

b) Use of touch devices with a pen to complete the worksheet for the pupil's own exposure.

c) Evaluation of acquired metrics.

\section{Experiment}

The aim of the experiment was to verify the relevance of the proposed methodology. The research focused on mathematics was used to assess relevance. Within this research, attention was paid to the application of the proposed methodology and the measured data were assessed in terms of their relevance to the verification of the methodology. The experiment was carried out on the following set.

The design and execution of the experiment was inspired by the publication of colleagues from the Palacký University Olomouc, who focus on the use of Eye Tracking in cartography [8].

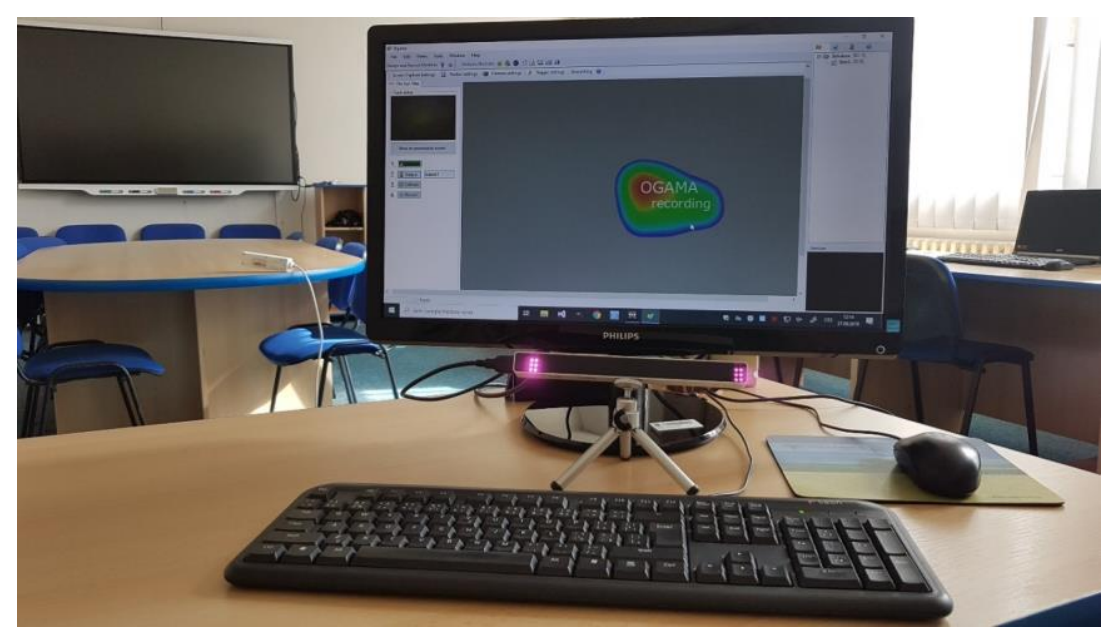

Fig. 1. Eye Tracker test set

Figure 1 shows the test station with the Eye Tribe ET1000. This device transmits the measured data directly to OGAMA 5.0. In this environment it is possible to perform an experiment evaluation. The Eye Tribe shows light sources of light whose reflection from the eyes is detected by the sensors. The correct position of the respondent is indicated by the panel on the left, which shows the correct eye catch, and which is shown in Figure 2. 


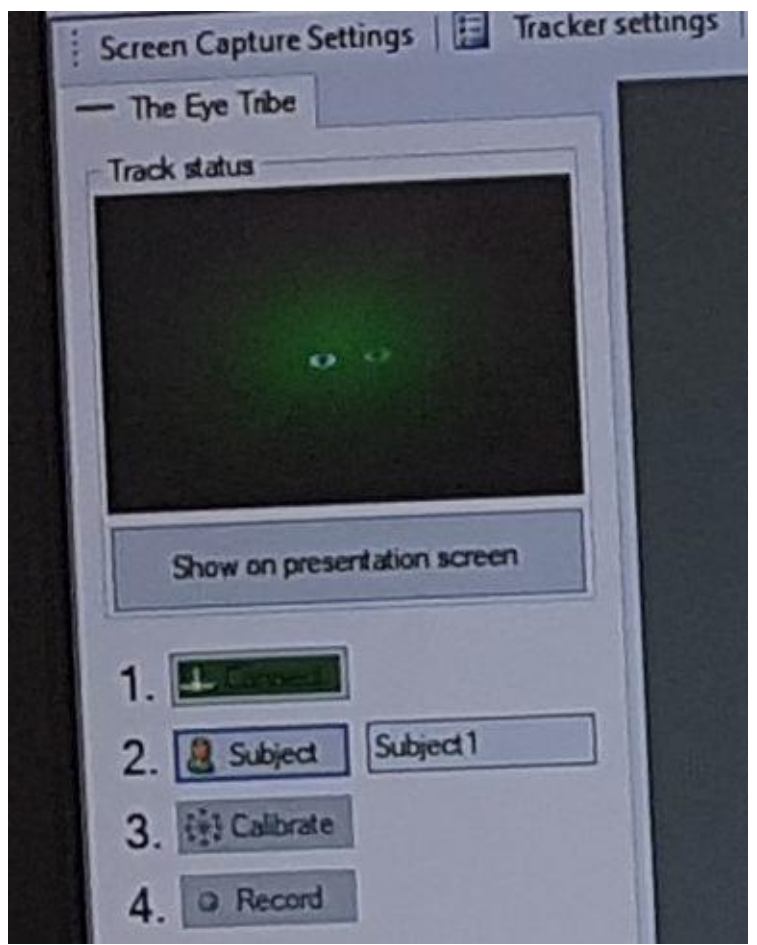

Fig. 2. Indications of caught eyes

Part of the software environment depicted in Figure 2 is also used to enter basic data about the respondent. Enter the name, surname, age, sex, optional class for classification and dominant hand in terms of use. Individual calibration is performed before entering this information.

\subsection{Construction of a test task}

In the experiment was used one test task in the field of mathematics, which was focused on understanding graphs. This task was represented by one film presented to respondents in Czech. The following image shows the English version of this image. 

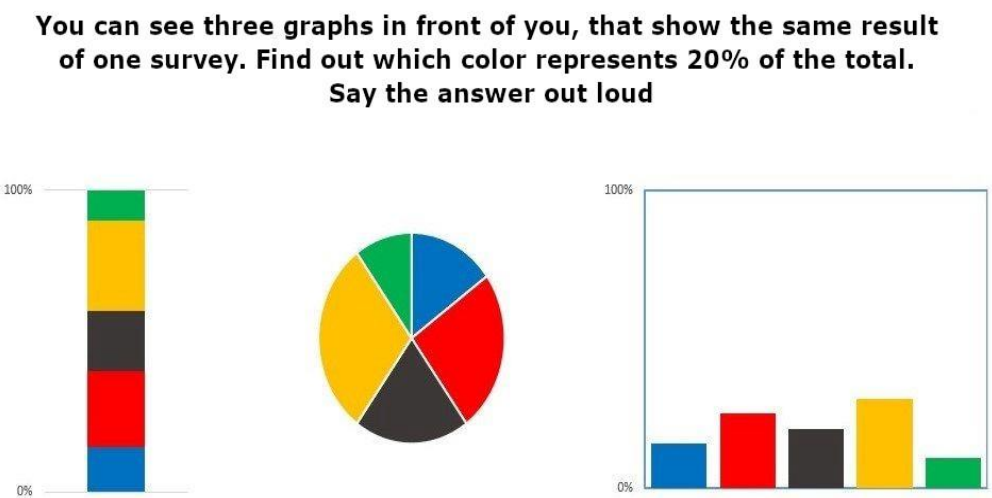

Fig. 3. The image of the test tasks

The recorded data in OGAMA 5.0 offers several types of output. The first type of output is an individual record of each respondent's behaviour, which is available as a video. A specific experiment can be viewed directly in the environment of the utility software and possibly consulted with the respondent. An example of individual output is shown in Figure 4.

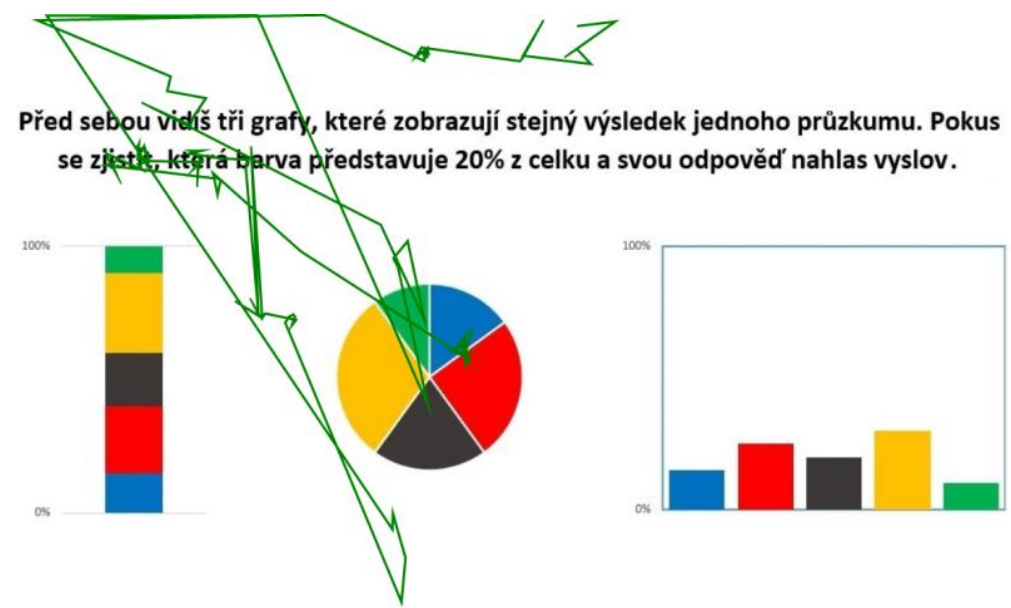

Fig. 4. Trajectory of eye movement of a particular respondent

The green line shows the trajectory of eye movement. Figure 4 shows the static situation and does not show the overall trend in the same way as in the video. In the context of this paper, it is therefore somewhat problematic to demonstrate such a dynamic variable as the trajectory of eye movement in a static image. In terms of aggregation of measured values, however, we can focus on the issue of identification, 
places where the respondent spent the most time - the so-called "attention map". By focusing on this variable, we get the following graphic result.

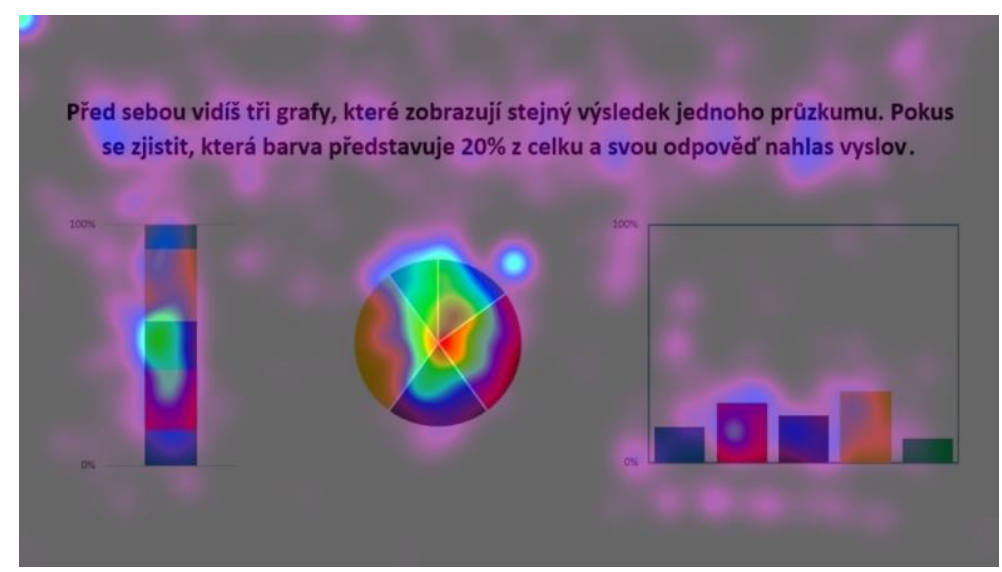

Fig. 5. Aggregated attention map

The bright spots of this map capture the attention of all respondents to the test images in each section. From the result it is clear that their attention corresponds with the task they fulfilled. In this case, the result is a time element that is crucial for our purpose. However, further processing is possible using a spreadsheet or database to which we transfer the measured data. Table 1 shows a sample of this data.

Table 1. Example of exported eye movement records in the test area

\begin{tabular}{|c|c|c|c|}
\hline StartTime & Length & Pos & PosY \\
\hline 166 & 67 & 391,7549133 & 224,9015656 \\
\hline 298 & 135 & 539,2806396 & 377,8653564 \\
\hline 498 & 101 & 285,1253357 & 350,3421326 \\
\hline 865 & 100 & 184,9478149 & 182,4914246 \\
\hline 1065 & 133 & 918,6416016 & 201,9309235 \\
\hline 1398 & 100 & 1122,663818 & 218,189621 \\
\hline 3097 & 66 & 317,0426941 & 191,3897705 \\
\hline 4594 & 68 & 931,2888794 & 440,2386475 \\
\hline 5728 & 66 & 243,3781738 & 188,0801239 \\
\hline 5928 & 66 & 573,2047729 & 239,1588898 \\
\hline 6027 & 68 & 703,6199341 & 243,9441376 \\
\hline 6427 & 67 & 329,857605 & 260,5488586 \\
\hline 6561 & 266 & 201,6452332 & 348,8861084 \\
\hline 9991 & 200 & 997,6365967 & 563,8207397 \\
\hline 10757 & 100 & 970,8223877 & 505,5331726 \\
\hline 11357 & 165 & 1024,460083 & 232,6972809 \\
\hline 11722 & 68 & 523,4381714 & 344,3972473 \\
\hline 11857 & 366 & 229,9851227 & 349,4264221 \\
\hline 12290 & 166 & 542,4595947 & 435,069519 \\
\hline 12490 & 266 & 552,8314819 & 422,7645874 \\
\hline
\end{tabular}


Table 1 shows part of the exported records that map the eye movement of the respondent. For these records, we always identify the start time of the action, its duration, and the coordinates that are related to the task. Such data from all users can be aggregated and returned to a clean task in OGAMA for interpretation.

The above-mentioned experiment was carried out on a sample of 33 university students. The group was represented by 20 women and 13 men, then 28 right-handed and 5 left-handed. The average age of respondents was 22.43 years.

\section{Conclusion}

The proposed methodology proved its functionality within the experiment and I believe it is applicable in the testing of teaching materials in terms of ergonomics and arrangement. This testing is relatively simple and is able to reveal trends in the perception of teaching materials in individual populations, or even better, in years of education. Based on the research according to this methodology, general recommendations for ergonomics and the organization of educational materials can be drawn up. In this experiment, the methodology was based only on eye movements. In the future, it is also possible to incorporate the movements of the mouse or equivalent device and it is possible, especially in the tasks that students perform, to define the area or areas of interest.

\section{$7 \quad$ References}

[1] Duchowski, A., (2017), Eye Tracking Methodology, Cham, Springer International Publishing AG.

[2] Hayhoe, M. M., Shrivastava, A., Mruczek, R., \& Pelz, J. B. (2003). Visual memory and motor planning in a natural task. Journal of vision, 3(1), 6-6. https://doi.org/10.1167/3.1.6

[3] Hládek, L., Porr, B. and Brimijoin, O. W., (2018) Real-time estimation of horizontal gaze angle by saccade integration using in-ear electrooculography. https://doi.org/10.1371/jour nal.pone. 0190420

[4] Holmqsit, K., (2011) Eye tracking: a comprehensive guide to methods and measures, New York, Oxford University Press.

[5] Luck, S. J., \& Hollingworth, A. (Eds.). (2008). Visual memory. OUP USA.

[6] National Institute for Education (August 2019), Kriteria kvality digitálních vzdělávacích zdrojů podpořených z veřejných rozpočtů, [Online].

[7] OGAMA, (August 2019), Open gaze and mouse analyser, Freie Universität Berlin. Available: http://www.ogama.net/.

[8] Popelka, S., (2018) Eye-Tracking (nejen) v kognitivní kartografii, Olomouc, Palacký University Olomouc. https://doi.org/10.5507/prf.18.24453132

[9] Rinehart, G., (2016) Quality education. Cary, Stormwatch.

[10] Supreme Audit Office of the Czech Republic (June 2019), Kontrolní akce č. 18/18, [Online]. Available: https://www.nku.cz/scripts/rka/detail.asp?cisloakce=18/18.

[11] Wall, K., Higgins, S., \& Smith, H. (2005). 'The visual helps me understand the complicated things': Pupil views of teaching and learning with interactive whiteboards. British jour- 
nal of educational technology, 36(5), pp. 851-867. https://doi.org/10.1111/j.1467-8535.20 $\underline{05.00508 . x}$

\section{Authors}

Pavel Smolka is member of the Department of Informatics and Computers, Faculty of Science, University of Ostrava.

Martin Žáček is member of the Department of Informatics and Computers, Faculty of Science, University of Ostrava

Petra Konečná is member of the Department of Mathematics, Faculty of Science, University of Ostrava. Vice Dean for the study Faculty of Science, University of Ostrava.

Article submitted 2020-10-14. Resubmitted 2020-11-13. Final acceptance 2020-11-15. Final version published as submitted by the authors. 